\title{
Melanoma and neural system tumor syndrome
}

INSERM

\section{Source}

INSERM. (1999). Orphanet: an online rare disease and orphan drug data base. Melanoma and neural system tumor syndrome. ORPHA:252206

Melanoma and neural system tumor syndrome is an extremely rare tumor association characterized by dual predisposition to melanoma and neural system tumors (typically astrocytoma; see this term). 